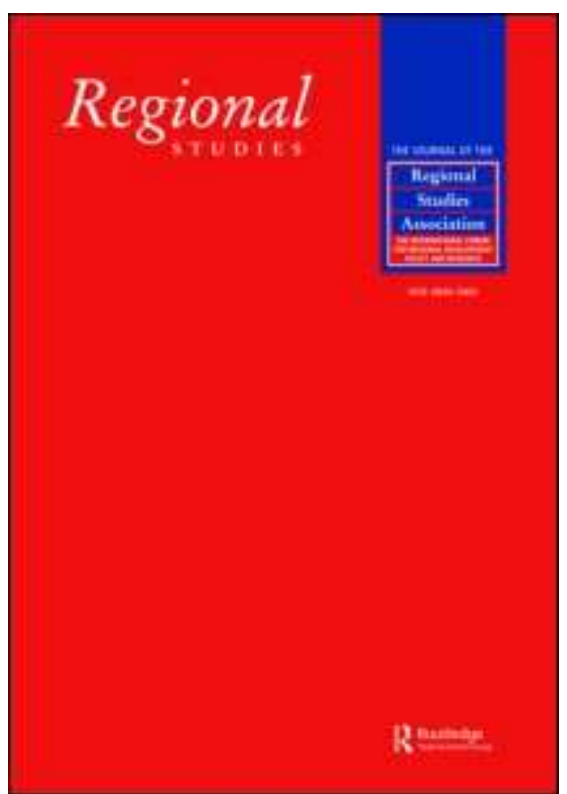

\title{
Gatekeepers of Knowledge versus Platforms of Knowledge: from potential to ealized absorptive capacity.
}

\begin{tabular}{|c|l|}
\hline Journal: & Regional Studies \\
\hline Manuscript ID: & CRES-2006-0147.R2 \\
\hline Manuscript Type: & Main Section \\
\hline JEL codes: & $\begin{array}{l}\text { L86 - Information and Internet Services|Computer Software < L8 - } \\
\text { Industry Studies: Services < L - Industrial Organization, L96 - } \\
\text { Telecommunications < L9 - Industry Studies: Transportation and } \\
\text { History < N - Economic History, O3 - Technological } \\
\text { Change|Research and Development < O - Economic Development, } \\
\text { Technological Change, and Growth }\end{array}$ \\
\hline Keywords: & $\begin{array}{l}\text { High tech clusters, Knowledge, Gatekeeper, Platform of } \\
\text { Knowledge, Sophia Antipols }\end{array}$ \\
\hline \hline
\end{tabular}

\section{SCHOLARONE Manuscripts}


Gatekeepers of Knowledge versus Platforms of Knowledge: from potential to realized absorptive capacity.

Nathalie Lazaric

GREDEG - University of Nice Sophia Antipolis and CNRS, 250 rue Albert Einstein, Sophia Antipolis, 06560 Valbonne, France, lazaric@gredeg.cnrs.fr

Christian Longhi (corresponding author)

GREDEG - University of Nice Sophia Antipolis and CNRS, 250 rue Albert Einstein, Sophia Antipolis, 06560 Valbonne, France, longhi@gredeg.cnrs.fr

\title{
Catherine Thomas
}

Université Paul Verlaine - Metz and GREDEG - University of Nice Sophia Antipolis and CNRS, 250 rue Albert Einstein, Sophia Antipolis, 06560 Valbonne, France, thomas@gredeg.cnrs.fr

First submitted: June 2006

Accepted: September 2007

\begin{abstract}
The development of clusters rests on geographical proximity, cognitive interactions as well as entrepreneurial initiatives. Sophia-Antipolis, a multi-technology cluster, is a good illustration of the type of challenges local systems of innovation face in creating positive knowledge externalities. This paper shows that if the existence of 'gatekeepers of knowledge' can generate the potential implementation of 'absorptive capacity', its effective realization requires some additional effort regarding the transfer of knowledge into the cluster. The concept of 'platform of knowledge' defined shows how a project of knowledge codification
\end{abstract}


could generate externalities by creating new opportunities for effectively combining and absorbing knowledge.

Key words. High tech clusters, Knowledge, Gatekeeper, Platform of Knowledge, Sophia Antipolis

JEL Code R11, O3, L20, L86

Résumé. Le développement des clusters repose sur la proximité géographique, les interactions cognitives et les initiatives des entrepreneurs. Sophia-Antipolis, un cluster fondé sur plusieurs technologies, est une bonne illustration des obstacles que les systèmes locaux d'innovation doivent franchir pour créer des externalités de connaissance positives. Cet article montre que l'existence de 'relais de connaissance' ('gatekeepers of knowledge') peut engendrer des capacités d'absorption potentielles, mais que leur réalisation effective implique des efforts supplémentaires relatifs aux transferts de connaissance dans le cluster. Le concept de 'plate forme de connaissance' proposé montre comment un projet de codification des connaissances peut générer des externalités en créant des opportunités nouvelles pour combiner et absorber des connaissances.

Mots clefs. Cluster high tech, connaissance, plate forme de connaissance, Sophia Antipolis.

JEL Code R11, O3, L20, L86

Die Entwicklung der Cluster hängt von der geographische Nähe, kognitiven Interaktionen und Initiativen der Unternehmer ab. Sophia Antipolis, ein Multi -Technologie Cluster, ist eine gute Illustration der Hemmnisse, die die localen Innovationssysteme überwinden müssen,um positive Externalitäten zu schaffen. Dieser Artikel zeigt, dass die Existenz von „Wissensrelais“ (,gatekeepers of knowledge“)potentielle Absorptionsfähigkeiten erzeugen 
Guardianes del conocimiento frente a plataformas del conocimiento: de la posible capacidad absorbente a una realidad.

Nathalie Lazaric, Christian Longhi and Catherine Thomas

Abstract.

El desarrollo de las aglomeraciones radica en la proximidad geográfica, las interacciones cognitivas y las iniciativas empresariales. Sophia-Antipolis, una aglomeración multitecnológica, ilustra a la perfección el tipo de retos a los que se enfrentan los sistemas locales de la innovación a la hora de crear efectos externos positivos de conocimiento. En este artículo demostramos que si la existencia de 'guardianes del conocimiento' puede generar la posible aplicación de 'capacidad absorbente', su realización eficaz requiere un esfuerzo adicional con respecto a la transferencia de conocimiento en la aglomeración. El concepto de 'plataforma del conocimiento' que se a definido muestra de qué forma podría un proyecto de codificación del conocimiento generar efectos externos al crear nuevas oportunidades para combinar y absorber eficazmente el conocimiento.

Key words.

Aglomeraciones de alta tecnología

Conocimiento

Guardián

Plataforma del conocimiento

Sophia Antipolis

JEL Code R11, O3, L20, L86 


\section{Introduction}

High technology clusters are strategic loci of creation of knowledge and resources. In the context of the 'learning economy' their role has recently been emphasized in France with the creation of the 'poles of competitiveness' 1 as keystones of regional policy. These 'poles' are supposed to be interconnected and open to their environment; such integration into global innovative networks appears to be an important condition for their viability. A vast amount of literature has emphasized the crucial role of space in building localized capabilities and learning (Maskell and Malmberg 1999, Keeble et al 1998 among others). In this context, space is no longer considered as a container but as a set of potential interactions between different sets of actors (Coffey and Bailly 1996; Rychen and Zimmermann 2006).

Our article aims to illustrate such interactions inside clusters; i.e. their ability to create local knowledge, to diffuse and absorb it during innovative projects. We shall show that these conditions may fluctuate according to the local organisational set ups implemented in the cluster. Indeed, Markusen (1996) has shown that different forms of territories could coexist. Consequently the same geographical area can evolve into diverse organizational forms depending on the specific small events and feedbacks in the area (Arthur 1990).

We shall illustrate why the development of clusters rests on the creation of local competencies through geographical proximity, cognitive interactions as well as entrepreneurial initiatives. We shall introduce the distinction between potential and realized 'absorptive capacity' (Zahra and George, 2002) so as to show the necessity of re-examining 
the notion of 'gatekeepers of knowledge' and of discussing its possible evolution into a new one: that of 'platform of knowledge'. The Sophia Antipolis Information and Communication Technology cluster (thereafter ICT cluster), one of the main European high tech centres, will be investigated. This cluster was created recently enough for us to provide an overview of its history, and of the 'small events' that have contributed to intensify its local interactions.

The first part of our article discusses issues related to knowledge at territorial level. Local systems, as well as what we understand as proximity, have evolved substantially over time, mainly because of the globalization of innovation processes that characterises modern economies. This is one of the reasons why knowledge codification may provide opportunities to change the traditional roles and may create a knowledge-fostering dynamic and a capacity to reinforce local competitive advantage. In the second section of the article, we provide an historical overview of Sophia Antipolis, so as to illustrate some of the local conditions that have contributed to transforming the 'satellite platform' into a 'platform of knowledge'. Finally, the third section contains a description of a specific dynamic at work locally that has contributed to the development of the ICT cluster. This dynamic will be illustrated through the presentation of the 'Knowledge Management Platform' project (thereafter KMP), which has generated various externalities.

\section{Localized learning and knowledge dynamic}

The creation of localized capabilities is a delicate process generating knowledge externalities that have to be channelled both inside and outside the cluster. In traditional districts 'gatekeepers of knowledge' assume this role. However the evolution of traditional districts and the creation of high tech clusters necessitate the development of new knowledge 
combinations so that their growth can be sustained. 'Gatekeepers of knowledge' may have some limitations in this cognitive process. Their transferring function may not always be effective in a network where knowledge has to be efficiently distributed. For this reason such actors could evolve by transforming themselves into knowledge creators. This requires a shift in their approach to knowledge sharing from closure to disclosure. The effective realization of 'absorptive capacity' by cluster's members plays a vital role in sustaining such entrepreneurial initiatives.

1.1. Knowledge platform or how to move beyond the traditional role of "knowledge gatekeepers'

How knowledge is created and diffused at local level is a crucial issue for academics, practitioners and politicians. This question is not new and has for a long time been discussed in the debate concerning the geography of innovation. Audresch and Feldman (1996), in a seminal work on R\&D investments underline the propensity for industrial activity to cluster spatially in order to benefit from knowledge externalities. However the real question is not that of the clustering effect, which has long been observed, but the differences in localization behaviours and in the ability to capture these externalities. These differences could be explained through the concept of 'knowledge filter', a concept that translates the diversity with which the different actors convert existing opportunities into real innovations and products (Acs et al., 2003). Indeed, the traditional rhetoric according to which can automatically be transformed into industrial products, is not sufficient to explain knowledge spillovers. New knowledge can be exploited by the actors but these opportunities, which have to be discovered, do not emerge spontaneously. On the contrary, before it can become an opportunity, knowledge has to be identified clearly. There is a filter between the stock of 
knowledge and its use, i.e. an absorptive capacity on the part of the recipient and the emitter for successful combination to occur (Acs et al., ibid).

The basic attributes of knowledge concern these various externalities and its potential openness. Knowledge is distributed among various decentralized units and needs to be shared and absorbed in a local context. As Schumpeter claimed long ago, knowledge has to be combined in order to produce innovation. This alchemy is far from automatic because some opportunity must pre-exist in order for viable interactions to occur (Nahapiet and Ghoshal, 1998). This shows that motivation is essential for such exchange to be beneficial. Indeed without the engagement of the firms and actors, knowledge will retain its "sticky" nature and will reinforce the 'knowledge filter' mentioned above (Szulzanski, et al, 2004).

If we assume that knowledge is distributed among various groups, communities or firms, knowledge is also spatially bounded. In this context, the globalization of innovation is concomitant with its localization emphasizing why both tacit and codified knowledge are necessary for sustaining knowledge creation ${ }^{2}$. Because of its complexity, the innovative process has to be regulated and coordinated, so that the 'absorption capacity' of each organisation can be increased (Cohen and Levinthal, 1990).

In the description of a Chilean cluster in Cochagua Valley, Giuliani and Bell (2005) define 'a cluster's absorptive capacity as the capacity of a cluster to absorb, diffuse and exploit extra-cluster knowledge' (ibid, p. 49). Firms with higher absorptive capacities are more likely to build external ties so as to reinforce their innovative capacities. The absorptive capacities of the local actors vary, preventing the uniform diffusion of knowledge. For example, some firms may transfer more knowledge than they initially receive and play an active role; others may act as 'net absorbers'. This variety generates an imbalance during interactions depending on the knowledge base of the firms and their position in the cluster. Certain firms may appear as 'technological gatekeepers' and may play a central role in the 
network in transferring knowledge while being strongly connected to external sources of knowledge; others are 'active mutual exchangers', i.e. characterised by the right balance of absorption and diffusion of knowledge, while others still may appear to play the role of 'weak mutual exchangers' with a balanced role of absorber. External stars have strong ties with external sources of knowledge and limited connections within the cluster, while isolated firms' have no strong connections either within or outside the cluster (Giuliani and Bell, ibid, p. 60).

This external openness however, is related to the territory's specificity. Usually industrial districts are characterised by an important degree of similarity between the knowledge bases of the various actors. In the Chilean Wine cluster, the main problem is that of renewing the traditional knowledge base by importing fresh ideas. In high tech clusters, the opposite situation may exist because firms have diverse knowledge bases with external connections and consequently need to increase their own interactions in order to combine knowledge efficiently. In spite of this significant difference, the question of the governance of knowledge - i.e. implementing common rules in order to enhance the actors' capacity to combine knowledge - is common to all clusters. In clear, 'technological gatekeepers' - in the sense given by Giuliani and Bell (ibid) - or 'knowledge gatekeepers' - according to Morrison terminology- do exist and are not just a fable. Let us be more explicit on their relative attributes.

The 'gatekeepers of knowledge' can be present during coordination and learning process (Allen 1977; Morrison 2004; Rychen and Zimmermann 2006). According to Morrison, gatekeepers constitute 'a small community, they are at the core of an information network, they are exposed to external sources of information, and the linkages they develop with external actors are mostly informal' (Morrison, ibid, p. 7). They are at the heart of the 
network and could either create 'network externalities' or restrict knowledge access intentionally or unintentionally. In effect they have various roles:

- a knowledge searching function for capturing external sources of information,

- a transcoding function for translating the meaning of such an information,

- a transferring function for disseminating accumulated and local knowledge (Morrison, ibid p. 8).

If this latter function is not realized, the existence of knowledge variety cannot generate new combinations and lead to a lack of local innovation.

In his seminal work on clusters, Porter has described their main attributes: their potential upgrading role, in the industrial specialization, through the presence of fruitful interactions concerning the demand side (Porter, 2000). These externalities result from the combinations of close and distant interactions, their mobilization materializing into local capabilities. The difference between traditional districts and high tech clusters resides in the latter's ability to provide new knowledge combinations adapted to future markets and future products present in the region. This local coordination and local entrepreneurship can be promoted by leaders firms or 'gatekeepers of knowledge' (Morrison ibid; Albino et al, 1996). However the 'knowledge filter' may obstruct the operation of a real transferring function between each local firms or institutions.

In order to avoid this problem, a 'platform of knowledge' could be built inside the cluster so as to regulate external and internal linkages. Its purpose is to overcome the traditional obstacles to cooperation, and promote the development of suitable interactions between the different sources of technological know-how, so as to reinforce the combinative capabilities, create viable rules and finally realize the transcoding and transferring functions. 
Our basic hypothesis, therefore, is that a cluster can benefit from latent 'network externalities' between organizations to innovate.

In high tech clusters, the main issue is not so much the creation of external links, which are already present, but the reduction of the 'cognitive distance' between firms that belong to various technological fields. A balance must be found between local and global learning within technological trajectories so as to facilitate the creation of new opportunities with existing knowledge bases. The network could be envisaged here as a means of going beyond the traditional dilemma between exploitation and exploration and of offering both specialization and variety generation:

'Networks offer the benefit of both specialization and variety generation. The superior abilities of markets to generate variety are a commonplace belief... The converse of this statement is that firms are superior vehicles for the accumulation of specialized learning... Specialization and variety are antithetical within the firm, but define complements within a network (...) network capabilities...are not specific to a firm, but represent joint gains to coordination and learning' (Kogut, 2000: 406).

The 'platform of knowledge' may regulate knowledge spillovers, by creating 'Marshallian externalities' related to gains of specialization and interactions between organisations that need to accumulate know-how in a specific technological field (the exploitation stage) or, on the contrary, by creating 'Jacobian externalities' that facilitate the search and exchange of complementary knowledge (the exploration stage). This trade off is crucial for coping with existing opportunities and for promoting evolution in the face of disruptive changes imposed by technological progress and globalisation (Iammarino and Mac Cann, 2006).

However the governance of 'network externalities' requires the development of specific capabilities to avoid the absorption of knowledge by a small group of firms. The 'platform of knowledge' may be designed via a codification of knowledge, which makes it 
possible to go beyond the traditional role of knowledge gatekeepers. Codification however is only one aspect of knowledge creation; the other is the development of shared knowledge and tacit knowledge between the members of a community (Lazaric et al, 2003).

Very recently the debate concerning regional knowledge platforms has galvanized the attention of some authors and has led them to explore possibilities of regional development involving various actors located within a cluster (firms, knowledge centre, research centre) (Hammaakorpi and Melkas 2005, Harmaakorpi 2006, Cooke 2006, Asheim et al 2006). In the case of Lahti in Finland, a regional platform has been developed to improve the absorptive capacity of the cluster by identifying the various existing tendencies and by elaborating various scenarios around the 'related variety' that could be created, reinforced or imagined (variety along the traditional technological trajectory or between various technological trajectories). The main objective is to look beyond this variety and 'enhance 'visualization' and 'potentialisation' for the region' (Cooke, ibid, p. 14). This highly empirical reflection emphasizes the importance of communication for preventing the emergence of the so called 'knowledge filter' and for benefiting from the real 'network externalities' that exist in the cluster.

The ambition of these regional development platforms is driven by the multipurpose character of technologies present at diverse stages of the innovative process (Boschma 2005). In order to exploit the generic technologies and their potential 'related variety', the platform is a stimulating organisational set up to transcend traditional sectoral policies and to exploit possible interrelatedness present inside diverse knowledge bases ( Asheim et al 2006; Nesta Saviotti 2006). 
1.2. Creating localized capabilities: from 'potential absorptive capacity' to 'realized absorptive capacity'

It is generally acknowledged that the development of high technology clusters is not a deterministic process, but the result of a chaotic and dynamic process through which activities are coordinated and a common language is developed. (Malmberg and Maskell 1999; Lorenzen and Foss 2003; Nooteboom 2003).

In effect a cluster

'... merges to the extent that a group of firms establish -intentionally and /or unintentionally- mechanisms of coordination that strongly reduce the various transaction costs involved in the process coordinating the process of innovation between legally independent firms, and where these coordination mechanisms a specific to the set of geographically bounded agents' (Lorenzen and Foss 2003).

This definition which goes beyond the classic argument of geographical proximity, promotes the entrepreneurial willingness to coordinate the division of labour in order to reduce transaction costs, create local capabilities and to diffuse a shared vision of business growth among diverse technological trajectories (see also Cooke 2003). In this sense, clusters are 'organized markets' aiming to reduce the cognitive distance between different firms (Maskell and Lorenzen, 2003). Cognitive distance plays a pivotal role here because it reinforces or reduces diversity within a network (Nooteboom, ibid; Kogut ibid), which may become an obstacle ${ }^{3}$. Consequently the nature and the importance of the 'cognitive distance' between firms are critical for reducing the 'knowledge filter' in a cluster.

Clusters are essential for the exploration of new opportunities and for helping firms to move beyond their traditional views of the market and technological trajectories. Firms can absorb new external knowledge by creating combinations with localised or external firms. In 
this sense, the cluster should not be reduced to a set-up stimulating the exchange of tacit knowledge and shared understanding, but should be sufficiently open to allow the dissemination of new ideas (be they tacit, articulated or codified). If openness is crucial for the exploration of external markets and to the understanding of a successful cluster, information accumulation however should not become a substitute for relevant knowledge ${ }^{4}$.

The creation of localised capabilities, the reduction of transaction costs and the building of a shared vision of the market for future technological opportunities, require an original form of knowledge lying between the tacit and codified types. Clusters offer such opportunities if knowledge is mobilized through local interactions and if existing potentialities are utilized. Let us be more explicit on this point. Knowledge base is the invisible part of the process which could be expressed in various competencies (technological, organisational, and relational ones). Competences are knowledge in use whereas the knowledge base is the vast amount not always materialized in the realization of products or technologies. Indeed before having access to some elements of the knowledge base and its possible interrelatedness, firms may have the opportunity to identify some competences present at the regional level for evaluating their fitness with their prior knowledge. The absorption of knowledge and is far to be an automatic procedure (Cohen and Levinthal 1990; Boschma 2006). For obtaining some local competitive advantage at regional level, firms have to mobilize energy to materialize potentialities inherent to their knowledge bases: i.e. their potential absorptive capacity -thereafter PACAP- (Zahra and George, 2002). The realization of absorptive capacity -thereafter RACAP- through effective innovation has to be initiated in order to be created. The passage from PACAP to RACAP is not only a period going beyond a simple discovery of knowledge base, but it also a stage where some competencies are integrated. We argue, here, that while leader firms play a crucial role in absorbing and 
enriching their own knowledge base, they may not have the motivation or the capacity to invest their energy in the local community.

Various reasons could explain such behaviour. First of all, accumulation and/or creation of knowledge may require some industrial prerequisites concerning the complementarity between the different knowledge bases. More generally, this argument concerns the knowledge-based industrial dynamics that make the process viable: the various stages of development in the ICT value chain for example, the technological strategy of each firm concerning the division of labour, the technological protocols facilitating or impeding such cooperation. Secondly, institutional barriers may hinder knowledge diffusion by preventing the disclosure of knowledge to the public or by creating a climate of suspicion against the diffusion of academics results, or simply because of the absence of any organization that would diffuse reliable information and knowledge to the local community (Krafft, 2004).

In a context where the diffusion and transfer of knowledge and know-how are difficult, the actors have to be motivated and committed. This dynamic can be created if the local actors benefit from working together in specific fields in order to create and develop specific innovative products and produce original combinations of know-how. A spirit of local entrepreneurship can emerge and enable the actors to convert this know-how into innovations, as long as the social mechanisms at work locally are able to support these exchanges and combinations. The transferring function can be fulfilled through the 'platform of knowledge', which may provide opportunities to conduct new knowledge combinations. It also creates some potential RACAP while generating indirect social integration mechanisms for maintaining social compromises, particularly those related to knowledge diffusion.

The following figure illustrates the mechanisms of absorptive capacity. 
$<$ Figure 1 here $>$

To summarize this debate, we argue that in a cluster, interactions and social integration mechanisms are created in a dual process. The first part of this process is related to the 'cognitive distance' that exists in the cluster, and the second part is political and related to an effective mobilization and engagement of the local capabilities in order to overcome the existing obstacles to cooperation (industrial and institutional ones notably).

2. Sophia Antipolis: from Satellite Platform to Platform of knowledge.

The story of Sophia Antipolis illustrates how the conditions of the creation or development of a localized knowledge base, the mobilization of internal or external knowledge, can change according the organisational design or innovation regime that prevail locally. If SophiaAntipolis, born as a 'satellite platform' following Markusen's typology, has evolved to a high technology cluster built around the telecommunication technologies, the presence of the 'knowledge filter' across the cluster significantly slows down the potential innovative process. The diversity of the knowledge bases is critical here for the creation of localized capabilities. The creation of a 'platform of knowledge' and the mobilization of various actors related to ICT cluster may contribute to reducing such variety by reinforcing the social mechanisms. The KMP project illustrates such a process of transformation of traditional 'gatekeepers of knowledge'. However as we will show, such a process is not an easy task and the mobilisation of local actors is a by-product of various events leading to the gradual emergence of local entrepreneurship.

2.1. From satellite platform... 
The choice of Sophia Antipolis for the development of a high-tech innovation cluster might seem strange at first sight, since the region had neither an industrial nor a university base. Nevertheless, the area did have some significant assets, including an international airport, a pleasant climate and a cosmopolitan tradition. However, apart from the existence of significant infrastructures nothing predisposed the region to high technology based economic development.

Sophia Antipolis was the result of a succession of 'small events' that occurred during the 1960s (for a detailed analysis of the Sophia Antipolis experiment see Longhi and Quéré 1994; Longhi 1999; Garnsey and Longhi 2004). A significant one, at the beginning of the process of development, was the establishment in 1960 of an IBM research centre near Nice. Texas Instruments soon followed IBM, a move that lent some credibility to the idea of a Sun Belt effect. Still, these ideas might have come to nothing were it not for the influence of one man, Pierre Lafitte'. He had a utopian vision of a rural 'Quartier Latin', a 'City of Science and Wisdom', and endeavoured to transform this vision into a project. Another decision proved crucial: France Telecom's decision to set up an infrastructure base in Sophia Antipolis was decisive in the creation of a national and international communication network.

Pierre Lafitte's ideas were diffused quite quickly. The project took off to a fast start thanks to the relocation of a number of external organisations into the area; these organisations were attracted by the quality of the infrastructures existing in the area. The French decentralisation process led to the relocation of several large public companies and laboratories. This process was later followed by a campaign to promote the region, with an emphasis on its climate attractiveness and its industrial facilities. Large multinational companies (mostly American) chose Sophia Antipolis either as their European administrative base or as a R\&D centre in charge of adapting their products to the European markets. Global 
firms invested heavily in the area, establishing self-contained units capable of operating without any local links.

The newly relocated companies had their own resources and their development could have been pursued with no interactions between them. All decision-making and industrial strategies were planned outside Sophia-Antipolis. So, despite the territorial proximity, the 'cognitive distance' between the various organisations (public and private) was significant in the early stages of development and the interactions between them sparse. These small events created a 'satellite platform' for using Markusen's (1996) taxonomy, i.e. a system directed from outside, rich in external connections but deprived of internal linkages. Despite this, a process that reinforced the early expansion soon set in. The agglomeration resulted in the emergence of two main clusters of technological activity. The first cluster comprises organisations specialised in the fields of computer science, telecommunications and electronics. It was this first cluster that provided the impetus for the growth of the project and structured the development of its industrial environment ${ }^{6}$. The second cluster is home to life and health sciences. Thus, Sophia-Antipolis was composed of independent co-located firms whose strategic choices were largely constrained by external decisions taken by the parent companies. Nevertheless, these initial conditions played an important role in developing future local and original resources (Longhi and Quéré, 1994).

\section{2. ... to crisis}

The limits to the growth of Sophia Antipolis were strongly related to the conditions under which it was created, i.e. lack of a local labour market, weakness of endogenous resources and scarcity of SMEs and specialized services. Over time however, the accumulation of economic 
activities on the site triggered a number of positive processes that mitigated these limitations until a crisis occurred in the early 1990s.

A first process was related to the human capital present locally. The arrival of public education and research institutes in Sophia Antipolis - as a result of the decentralisation policy- (the Ecole des Mines, the CNRS and the INRIA ${ }^{7}$ ) play an important role in sustaining endogenous growth. INRIA in particular played a fundamental role in structuring local technological development, thus favouring the emergence of an endogenous innovative capacity and local start-ups. However, this potential proved to be rather insufficient to train the graduates required for the development of a local labour market. A significant event in this regard was the decision to move some of Nice University's research institutes and PhD's programmes to Sophia-Antipolis. The shift, which began in 1986, soon reached a critical mass.

A second element was the creation of service activities. Despite its heterogeneity, this activity has grown significantly since 1982 . Today, it represents $28 \%$ of all jobs and more than $50 \%$ of all firms. Its growth can be partly explained by a catch up effect, due to the original absence of services in a 'greenfield' site like Sophia-Antipolis. These various elements have contributed to the reversal of the site's established trends of exogenous oriented development and to the creation of some localized capabilities able to sustain local innovative processes. However, in the 1990s doubts were raised concerning these developments.

The crisis that characterized the early 1990s had a considerable impact on SophiaAntipolis. First, the crisis struck at the heart of the project's growth engine - i.e. the computer science activities - which forced many large firms to downsize. Secondly, it gave rise to serious doubts as to the validity of the project's development strategy, which was essentially a marketing strategy attracting investments from large firms. Whereas the 1980s had been 
characterized by multinational developments driven by market processes, the 1990s brought on new forms of globalisation.

The nature of the globalisation process in high tech activities changed dramatically in the 1990s (Veltz, 1993; Longhi, 2003; Maskell and Malmberg 1999) and the creation of localized innovative activities proved to be crucial. As the development of specific capabilities and knowledge is critical, location does matter. This explains why a new development strategy, based on local resources and competencies, had to be generated. In this context, knowledge creation and absorption became critical for the viability of the cluster, generating a suitable balance between local and global interactions (Rychen and Zimmerman, 2006). Historically, only external relations seem to have been extensively developed, whereas relations of proximity were underdeveloped, which prevented the development of social integration mechanisms.

2.3. ... and to the emergence of the future platform of knowledge

Following a period of instability in the early 1990s, new dynamics emerged in the area. The growth regime shifted from exogenous to endogenous dynamics, and new interactions between local firms and/or research institutes were generated (Garnsey and Longhi 2004). The constraints were no longer related to a simple question of attractiveness, but to innovation and knowledge, and its specific coordination. An important part in this change was played by the park's professional associations, which initiated the development of local interactions.

The roles of the various business associations and clubs shifted from the traditional lobbying to more collective and coordinated initiatives. The Telecom Valley Association was one of the first initiatives in this regard. Originally created by the seven local telecommunication majors, it now includes all the local actors in the field, be they public or 
private, large or small organisations. Faced with a rapidly deteriorating economic position and the risk of having to relocate away from the park, this network attempted to make visible the local competencies that the actors had accumulated over time in the field of telecommunications. This generated important externalities between the members of the network and enabled them to share technological visions and resources and combine complementary know-how. Today the area is a strategic centre for telecommunication activities in Europe, with a specific advantage in wireless technologies. The main European institutions defining the standards for telecommunications (ETSI) and Internet (WWW) are located in Sophia Antipolis; this places the technopole at the heart of the innovation process and makes it a strategic area for gathering information on future technologies. Telecom valley is not the only organisation of its type: a number of associations and clubs connecting SMEs (Imet, MITSA), research institutes (Persan) or specific technologies (Club Hi-Tech), with the explicit aim of promoting networking and local collective learning processes, are present and play a fundamental role in coordinating the innovative activities of firms, in providing information about both technologies and markets and in developing local ties.

Another important evolution is related to the creation of new SMEs. Historically, spinoffs were restricted to research institutions but the crisis shifted this process towards large firms. Paradoxically, this creation of new SMEs occurred in the early 1990s, a period during which employment growth slumped and large firms began downsizing and outsourcing. A wave of 'forced' spin offs gave rise to the creation, by engineers formerly employed by the large firms ${ }^{8}$, of local start-ups in software, multimedia, telecommunication and Internet technologies. Though several of then subsequently disappeared with the end of the bubble and euphoria concerning the 'new economy', the dynamic of creation of new resources was maintained and was no longer restricted to large firms. 
The shift towards an endogenous growth regime could not have occurred if the area's training and research capabilities had not been developed or in the absence of industrial interdependence. The existence of a local labour market, allowing for skilled labour mobility, contributed to local development by facilitating the diffusion of tacit and technological knowhow (Keeble et al., 1998). In addition to the qualified human resources supplied by the higher education institutions, the process of downsizing and externalisation initiated by the large firms led to the emergence of new qualified human resources in the local labour market ${ }^{9}$.

Overall, it has been observed that in the cyclical downturn the IT sector experienced in the mid 2000s did not, actually, affect the cluster. A number of IT firms in Sophia Antipolis continued to grow with only a slow decline in their activities, which could be interpreted as a sign of the good functioning of localized innovation activities (Krafft, ibid). The recent move of several multinational firms to Sophia Antipolis is the ultimate confirmation of the park's technological and innovative potential and its position as 'pole of excellence' paves the way for the acknowledgement of local capabilities. Indeed, the arrival of new firms involves neither large investments nor the simple adaptation of existing products or services; they tend to settle in the park as tenants with small units and grow locally drawing on local capabilities.

Growth, almost exclusively endogenous, is now the result of local processes inside the cluster (Garnsey and Longhi, 2004). Moreover, expansion and high skills are concentrated in the information technology sector ${ }^{10}$. The emergence this new regime and of new institutional arrangements following the crisis shows that the resources accumulated in the 1980s were sufficient to reconfigure the 'satellite platform'. Whereas public intervention had prevailed at the beginning of the project, the process is now somewhat self-organised and driven by private firms. In order to reinforce regional localized capabilities, Sophia Antipolis has to build networks that will make it possible to sustain innovative activities with local partners. 
The Telecom Valley especially, and other associations, have played a key role in changing the coordination processes that prevail in the system with the elaboration of a 'platform of knowledge'. Some pivotal firms have developed decisive innovations, related to mobile technologies especially, or introduced new forms of knowledge in the area. 'Gatekeepers of knowledge' have emerged and present many similarities with the organizational set up defined by Morrison (ibid) due to vertical cooperation. Furthermore, the new ICT cluster is based on different interconnected, but 'cognitively distant' technologies ranging from microelectronics to telecommunications and software. The evolution from geographical proximity to organized proximity is not a sufficient condition for the emergence of knowledge and innovation from interaction of local firms or actors: face-to-face interaction between two actors cannot alone generate synergies; the latter can only develop between two individuals who share common representations (Torre and Rallet, 2005). These different sectors have had to coordinate their $\mathrm{R} \& \mathrm{D}$ activities in mobile and Internet related technologies for exploiting the 'related variety' present in the cluster. This technological necessity has forced the associations and actors of Telecom Valley to get involved at local level. However, some horizontal processes were still lacking for facilitating the absorption of different knowledge bases across the different sectors.

Indeed, most of the endogenous growth has taken place through vertical productive relationships in a number of specific technological trajectories. The potentialities provided by the presence in Sophia-Antipolis of the main actors in ICT were not fully utilized; that is why it was necessary to find a way of sharing different knowledge bases and of reducing the cognitive distance. In this regard, the 'platform of knowledge' implemented by Telecom Valley has devoted itself to reinforcing the linkages between the different actors present in the area and to promoting and maintaining future collaborations through the implementation of ICT tools. Knowledge needs to be shared before it can be applied and commercialised inside 


\section{The KMP Project}

The Telecom Valley association has grown rapidly as a main force in the collective dynamics of Sophia Antipolis. It has promoted the development of socio-economic linkages between the different actors (public and private, large and small organisations) of the telecom cluster and is akin to a self-organized project born from the constraints that emerged during the crisis. KMP is an intentional attempt to implement social integration mechanisms that will enable the firms to enhance their capacity to combine knowledge absorptive capacity.

3.1 The KMP Project as a 'boundary object' that reinforces social integration mechanisms

At the beginning of the new millennium Telecom Valley's objective was to increase innovation and technical knowledge by establishing collaborative agreements between academic and industrial players. This objective emerged because of the perception that a network could facilitate the development of informal interactions and therefore promote mutual understanding within and between the various technological trajectories present in the area - which by nature represent a multi-technological field. Unlike industrial districts, the firms in the Telecom Valley belong to different professional groups and so share neither a similar vision concerning the implementation of innovative projects nor any communication 
codes. For this reason, measures must be taken to facilitate knowledge transfer among the various technological poles, so that new knowledge combinations and innovation can be generated. In other words this includes the transformation of PACAP into RACAP. This requires an increasing commitment of and an immaterial investment by all the local actors in order to overcome the 'knowledge filter'.

\subsubsection{The goal of the KMP project}

The KMP Project, which was launched in 2002 and ended in 2005, is a good illustration of this new initiative ${ }^{11}$. Indeed, its objective was to elaborate an innovative Knowledge Management Solution, including a map of the competencies present in the Telecom Valley that would help identify the actors and projects, while facilitating cooperation. KMP is in fact an experimental ICT infrastructure: a semantic web service of competencies enabling networks of firms with different objectives to collaborate by guaranteeing information consistency without requiring the diffusion of strategic information. The project had several objectives, in particular:

- a description of firms' competencies (technical, organizational and relational ones) in order to increase mutual understanding,

- the development of a common language to facilitate exchange and the combination of competencies,

- the elaboration of a shared business vision, including an common understanding of market characteristics and customer needs in order to accurately identify innovation opportunities.

In order to promote the combination of competencies within the cluster, the project aimed to develop not only cooperation between the firms but also between the industrial and 


\subsubsection{Methodology: History of the project and position of researchers}

The project was initiated by a few firms and driven by academic partners. Two of the authors of this article have been involved in the project: one was the KMP coordinator and played the role of intermediary between academic and industrial partners (public or privates ones); the other, had a more discrete role of observer; they followed the various stages of the project and reported on the different opportunities provided and limitation associated with knowledge codification. This direct involvement enabled us to collect a vast amount of data drawn from interviews conducted at different stages of the project: at the beginning, during the development of the ICT tool and after its launching in the cluster.

Indeed, inside the KMP project a methodology to implement a design research in the specific case of the building of an artifact has been developped ${ }^{14}$. The design process (designers' world) is composed of iterative loops (Akrich et al., 2002) ${ }^{15}$. The users' world represents the socio-technical network that supports the process of innovation. Users-pilots (or lead users) are not the only components of this socio-technical network. In this perspective, the success of a design project depends on the 'art of interessement' i.e. to enlarge the socio-technical network. To sum up, six main steps composing the design methodology have been implemented: 
1. The feeling of discomfort - to analyze the specific managerial problem to solve.

2. Building a theoretical support - as underlined by Romme and Endenburg (2006), this step consists in building construction principles and design rules.

3. Uses scenarios - they focus on the interaction between a system and its environment.

4. Building archetypes - in the specific case of an ICT tool design, these archetypes consist of the successive prototypes (including user interfaces) resulting form the co-evolution of the designers' world and the users' one.

5. Experimentation - two complementary but no sequential phases composes this step: on the one hand, interesting a growing number of heterogeneous actors (users, professionals, bureaucrats, granters ...); on the other hand, evaluating the successive prototype.

6. The change process - the adoption-adaptation process progressively spreads and transforms the organizational context. These transformations lead to an evolution of the managerial problem, which results in a new design loop.

Four loops have composed the KMP project: the first (2001/2002) has concerned the elaboration of the project and the last (2005/2006) the transition phase has formed the prototype to its industrialization. Loops 3 (2003) and 4 (2004) were the core years of the design process. During these two loops 3 uses scenarios were built ${ }^{16}$.

A large number of interviews were conducted formally in order to identify the needs of Telecom Valley and the objectives of the tools (see in appendix 1, the details and number of these interviews). The objectives evolved with time. For example the initial aim of the project was limited to the construction of a simple 'boundary object' (Cacciatori 2003). This objective was surpassed and was expanded to the more ambitious development of a platform of knowledge. In short, KMP initially assumed the searching and transcoding function but, as 
a result of its success the project shifted progressively to a transferring function. Let us be more precise on this point.

The goals of the project evolved according to the different, cognitive or political, constraints. Indeed the ideas and potentialities of such a 'platform of knowledge' were unknown at the beginning and were discovered over time during the co-development of the prototype. For example, in 2002, Telecom Valley association suggested that the KMP project capture competencies in order to facilitate the identification of project partners. Progressively, however, the project shifted toward the analysis of the cluster dynamic through the identification of new value chains among the various technological poles (microelectronic, computer science and telecom $)^{17}$.

3.2 Building a common space: generating and maintaining knowledge exchange and combination

An important characteristic of clusters is their ability to create a space for collective learning and to promote knowledge sharing. Dyer and Nobeaka (2000, p.353) underline that knowledge sharing is facilitated if the actors can reach a shared representation of space. The 'platform of knowledge' generated many opportunities for the cluster, particularly through emergence of a common representation of an open space with evolving boundaries. This shared representation was developed in two stages, first, the representation of the telecom value chain, drawn up in collaboration with local actors ${ }^{18}$, second, the representation of the Telecom cluster, including all the cluster's stakeholders:

- Local Development Institutes (LDIs) in charge of promoting the cluster abroad and attracting foreign investment and companies. Clubs and associations in charge of reinforcing 
exchange in the cluster. These are considered to be the 'facilitators' of the relationships established between academia, industry and consumers;

- Research Institutes and Telecom Standards Institutes, considered to be stakeholders; indeed, the Research Institutes can benefit from partnerships with industrial actors and Telecom Standards Institutes in their elaboration of new technological standards;

- Consultants in the domains of law, finance and management; they have a supporting role and help ensure an efficient management of the economic and non-economic linkages in the Telecom Value Chain.

The characteristics of the Telecom cluster are summarized in the figure below.

$<$ Figure 2 here $>$

The collective representation has been the result of many interactions between the Telecom Valley association and KMP's advisory board. This figure, which has been a preliminary result of the project, shows the configuration of exchanges that occur in this sector. Indeed, starting with the end-user consumer (1), the value chain leads to seven nodes, which are main sources of value creation. These are: Internet Access and Service Providers (2); The Value-Added Re-sellers (3), the distributors that play an active role between the enduser consumer and the terminal device (especially in guaranteeing information exchange); the Content Providers (4); the Network Operators and Telecom Service Providers (5); the Terminal Device Manufacturers (6); the Network Infrastructure Providers (7); and finally the Application Developers (8). Most of the actors located in Sophia Antipolis belong essentially to nodes 5, 6, 7 and 8 , though some start-ups have begun developing node 4 i.e. software applications. Of course this local representation of actors might not fully correspond to the overall situation in which the firms find themselves at the level of their group. ${ }^{19}$ 
In 2004, all the firms of Telecom Valley -as well as the 11 KMP project's pilot firms were asked to position themselves on this value chain. As a result, the members of Telecom Valley adopted this value chain as their own. This shared representation of collective space reinforced the collective identity and influenced the strategies of cooperation. For example, the subsidiary of an American multinational group, which had been hesitant at the beginning of the project, became eager to be a 'lead user' when it eventually managed to position itself in the collective space.

Similarly, the shared representation of the Telecom Cluster has made it possible to determine the boundaries of the Telecom Valley community. The ability to share this representation has even become a sine qua non for becoming a member of Telecom Valley. These shared representations motivate the firms to engage locally as they enable them, be they industrial or academic organisations, to position themselves in the regional cluster.

Local actors may be aware of the effects of critical mass and of possible deficiencies in certain technological fields, which in turn enables them to envisage new combinations with other territories that might possess complementary competencies. In Sophia Antipolis, most firms operate on segments 5, 6, 7 and 8. It is at the level of information providers (segment 4), of IAP/ISP (segment 2), of firms that commercialise and/or assemble office and computer equipment (segment 3) that these complementary competencies are needed. Telecom Valley, which initially struggled to define itself, was reluctant to accept new members. Today however, thanks to the modelling of the common space, Telecom Valley has opened its doors to new members, and particularly to multimedia firms (segment 4). In this regard, the shared image of the value chain facilitates the identification of value-adding knowledge combinations and results in a shared visualization of these opportunities, which reduces the knowledge filter and enhances the cluster's absorptive capacity (Zahra and George, ibid). 
3.3 Codification of knowledge and the emergence of new forms of governance

Once the perimeter of the selected space has been determined, a portfolio of potential competencies can be defined in order to foster interactions through which collaborations can emerge (Nahapiet and Ghoshal, ibid). This representation is not only cognitive but also political, because it helps to identify the potential knowledge combinations among various and complementary resources used in different projects. For example, some interactions have been fostered in order to solve various problems such as:

- finding a suitable way of adding value to individual corporate competencies,

- finding a partner for solving problems in areas where internal competencies are insufficient, - gaining a better understanding of partners' needs in order to improve the description of internal competencies,

- sharing resources in order to better exploit network competencies,

- creating a shared vision of the market in order to develop present and future projects.

\subsubsection{A partial and limited disclosure of knowledge with an abstract representation of} competencies

This codification had various objectives. Indeed the KMP project was a regional 'platform of knowledge' used by local actors in order to enhance their absorptive capacity at a local and a corporate level. The collective representation was aimed not to codify know-how but rather to identify competencies in order to combine them more accurately. This delicate process was achieved through a partial disclosure of information and a strategic approach to knowledge diffusion: competencies should not be described in depth and exhaustively; however, their description must be precise enough to make these competencies visible. This kind of approach 
also opened opportunities for communication between firms, which can thus join the cooperation process and find a suitable way of representing their activity.

Knowledge and competency are difficult to disentangle from specific contexts as knowledge travels on the rails laid down by practice. They are difficult to separate from their original context and consequently difficult to articulate and codify. Nevertheless, an abstract representation -or ontology-, even if incomplete or partial is necessary in order to identify them. So, articulation and codification can be useful even though they are intrinsically complementary to the production of tacit knowledge (Lazaric et al., ibid).

For this reason, an abstract representation of competencies based on four points: (1) action, (2) key resources (technological, organizational or scientifically resources), (3) deliverable, and (4) business activity, was put forward (Rouby and Thomas, 2004). These levels of abstraction have made it possible to identify the competencies and to compare them, taking into account the interests of the different actors looking for them. Once competencies were identified and located, a precise description was suggested including details on resources, patents, publications, $\mathrm{R} \& \mathrm{D}$ collaboration, and industrial partnerships. This additional information was essential to a proper understanding of a partner's competencies and was effectively based on 'know-what' (see Lundvall and Johnson 1994, on this point). So, the codification used did not disclose the strategic aspects of a firm (its 'know-how' and 'know-who') but communicated a part of the relevant knowledge, a kind of 'show-how' put in place to help actors in the cluster identify which organizations have certain competencies and where they can be found (Roberts, 2000).

\subsubsection{The local actors' involvement in the codification process.}


An important outcome of the KMP project was also that it revealed the nature of the various existing competencies, in other words, their similarity and complementarity, in Richardson's sense of the terms (1972). The similarity had to do with the competencies that shared the same resources and actions whereas the complementarity was had to do with the competencies found in the ICT sector that could be shared among different organizations. The KMP project also publicized the existence of a need, within the Telecom Valley association, for an understanding not only of the nature of competencies inside each firm but also of the possible critical masses and complementarities. This leads local actors to increase awareness of some of the cluster's strengths and weaknesses ${ }^{20}$.

Moreover, by making those competencies more visible and by creating new forms of governance within the Sophipolitan cluster, the concepts of similarity and complementarity have also had some structural effects within the cluster. For example SAME (Sophia Antipolis Micro Electronics) is an association set up recently in order to reinforce $R \& D$ policy within the microelectronic sector. This initiative was perceived by Telecom Valley as representing a potential obstacle to visibility within the cluster. Telecom Valley argued that different associations might hinder interactions (by introducing an overly fragmented new division of labour within the cluster). This dispute was finally solved by clearly establishing the different roles of the various associations in the cluster. Associations like SAME play a crucial role by promoting technological innovations, others like Hi' tech or Telecom Valley have of a more horizontal role, orienting markets and defining the future uses of some products' innovations. So, the KMP project has given rise to a process of knowledge articulation and codification among its members; it has structured the Sophiapolitan cluster and transformed the role of the different associations by defining their specific role in supporting knowledge combination or in orienting the long term strategy of firms more clearly. 
More generally, the creation of a common language and the introduction of the concepts of similarity and complementarity have enabled the various actors to improve their ability to anticipate the value created by partnerships, by increasing their capacity to detect the best opportunities and prospects. In 2005, for example, firms and organisations operating in the PACA region ${ }^{21}$ adopted and started using these concepts so as to be able to participate in the national project of 'poles of competitiveness', and particularly those of the SCS pole 22 . These concepts enabled them to structure the presentation of the cooperation projects within the SCS pole. Two types of projects were identified: the user oriented projects (i.e. combining complementary competencies) and the technology oriented projects (i.e. combining similar competencies and aiming for technological innovation)

Finally, through the establishment of a multi-sectoral ontology, which became the common language of the actors involved, the KMP project directly facilitated the identification and possible combination of technological competencies, and thus reduced the cognitive distance. Through this process of articulation, which was implemented prior to the codification, new tacit knowledge emerged and thus reinforced the local entrepreneurial dynamic $^{23}$. The tacit knowledge, produced through the processes of social integration, enabled the local actors to create an effective 'platform of knowledge'.

\section{Conclusion}

The history of Sophia Antipolis illustrates the evolving constraints a high tech cluster must face in order to generate innovation and growth. We have described, in this article, the gradual transformation of a 'satellite platform' into a high tech cluster with the emergence of localized capabilities embedded into global innovative networks. The KMP project provides a 
good example of such regional mobilization. Indeed 'gatekeepers of knowledge' have transformed some of their specific attributes by disclosing more knowledge. Their behaviours were not entirely motivated by philanthropy but rather resulted, from an acknowledgment of the spatial dimension of innovation and from the understanding that new rules of the games have to be implemented in this 'organised market'.

The 'knowledge platform', which has facilitated the implementation of a regulation of external and internal links, facilitating the combinative capability and fulfilling the transcoding function, is illustrative of this new form of governance. Though the transferring function might be more difficult to evaluate right now with only a qualitative case study, the emergence of a new collective interactive dynamic inside the cluster is not at all neutral. Indeed, the KMP project has contributed to the emergence of this new dynamic at two levels: at cognitive level and political level.

First of all, the different representations of the collective space have had an effect on the emergence of a collective identity, by making sense of the logics of action and by reinforcing the actor's commitment to the community.

Secondly, the development of a common language (ontology of competencies, concepts of similarity and complementarity) reduces the cognitive distance between the various entities and the 'knowledge filter' by creating a shared representation of the technological, scientific and managerial resources available in the cluster and of the knowledge combinations that can potentially create value. The creation of a common language has offered the local actors the possibility of benefiting from both 'Marshallian externalities' (exploitation of the same technological trajectory) and 'Jacobian externalities' (exploration of new combinations). 


\section{References}

Albino V., Garavelli A.C., (1999), Knowledge Transfer and inter firm relationships in industrial Districts: the role of the leader firm, Technovation, 19, 53- 64.

Allen, T. J. (1977), Managing the flow of technology: technology transfer and the dissemination of technological information within the R \& D Organization. MIT Press

Acs Z., Audretsch D., Braunerhjelm P., Carlsson B. (2003), The missing link: the knowledge filter and endogenous growth, Working paper presented at the Druid summer conference on Creating, sharing and transferring knowledge. The role of Geography, Institutions and Organization.

Akrich M., Callon M., Latour B., 2002, The key success in innovation Part I: the art of interessement. International Journal of Innovation Management, Vol.6, n², pp. 197-206.

Arthur B. (1990), Silicon Valley Locational clusters: when do increasing Returns imply monopoly, Mathematical Social Science, Vol. 19 n $^{\circ}$ 3, March, 116-131.

Asheim B., Coenen L., Vang J. (2005), Face-to-Face, Buzz and Knowledge Bases: Socio-spatial implications for learning and innovation policy, CIRCLE Working Paper 2005/ 
Asheim B. et al, (2006), Constructing Regional Advantage. Principles, Perspectives, Policies, Report for the Directorate-General for Research, European Commission, Brussels

Audretsch D. B., Feldman M. (1996), R\&D Spillovers and the geography of innovation and production, The American Economic Review, vol. 86, n 3, 630-640.

Bathelt H., Malmberg A., Maskell P. (2002), Clusters and Knowledge Local buzz global pipelines and the process of knowledge creation", DRUID working paper. Available through <www. Druid.dk.

Boschma R.A., 2005, Proximity and Innovation: A Critical Assessment, Regional Studies, Vol. 39.1, February, 61-74,

Bresnahan, T., Gambardella, A., Saxenian A (2001), Old economy inputs for new economy outcomes: cluster formation in the New Silicon Valleys, Industrial and Corporate Change, 10.4, 835-860.

Cacciatori E. (2003), Organisational memory in innovative project based firms: a boundary object perspective, Paper presented at the DRUID Conference, June 12-14, <www.druid.dk>.

Coffey W., Bailly A. (1996), Regional Science: back to the future? The annals of Regional Science, vol. 30, Issue 2, 153-163.

Cohen W., D. Levinthal. (1990), Absorptive capacity: a new perspective on learning and innovation, Administrative Science Quarterly, 35(1), 128-152.

Cooke P. (2003), The role of Research In regional Innovation systems: new models meeting Knowledge Economy Demands, Regional Industrial Reports, Cardiff University.

Cooke P. (2006), Between implicit and explicit knowledge: translational proximities and innovation, Working paper DIME COPs: a driver for innovation and Competitive advantage, October 27-28.

Dyer J.H., Nobeoka K. (2000), “Creating and Managing a High-performance Knowledge-sharing Network: The Toyota case", Strategic Management Journal, 21, pp. 345-367.

Garnsey, E., Longhi, C. (2004), High Technology Locations and Globalization: Converse Paths, Common Processes, Int. J. Technology Management, Vol. 28, nº 3/4, 336-355

Giuliani E. and Bell M. (2005), The micro-determinants of the meso-level learning and innovation: evidence from a Chilean wine cluster, Research Policy, 35, 47-68.

Haarmakorpi V. (2006), Regional development Platform method (RDPM) as a tool for Regional innovation policy, European Planning Studies, 14, 8, 1085-1105. 
Haarmarkorpi V. Melkas H. (2005), Knowledge management in regional networks: the case of Lahti, European Planning Studies, 15, (5), 641-660.

Hatchuel A., 2005, Towards an epistemology of collective action: management research as a responsive and actionable discipline. European Management review, vol.2, pp. 36-47.

Iammarino S., Cann P. Mc (2006), The structure and evolution of industrial cluster: transactions, technology and knowledge spillovers, Research Policy, 35, 1018-1036.

Johnson, B., Lorenz, E., Lundvall, B.-Å. (2002), Why all this fuss about codified and tacit knowledge?, Industrial and Corporate Change, Vol. 11, no. 2, 245-262.

Keeble D. et al. (1998), Collective learning processes and inter-firm networking in innovative hightechnology regions, ESRC Centre for Business Research, WP 86, March.

Kogut B., (2000), The network as knowledge: generative rules and the emergence of structure, Strategic Management Journal, 21, 405-425.

Krafft J. (2004) Entry, exit and knowledge: evidence from a cluster in the info-communication industry, Research Policy, 33, 1687-1706.

Latour B., (1989) La science en action, Gallimard.Paris.

Lazaric N., Lorenz E. (1998), The learning dynamics of trust reputation and confidence, in Trust and Economic Learning, Lazaric and Lorenz (eds) Edward Elgar, London, 1-20.

Lazaric N. (2003), Trust building inside the epistemic community: some investigation with an empirical case study, forthcoming in F. Six and B. Nooteboom (eds), The Process of trust in organizations", Edward Elgar, Londres.

Lazaric N., Mangolte P.A., Massué M.L. (2003), Articulation and codification of collective Know how in the steel industry: some evidence in the French blast furnace, Research Policy, 32, 18291847.

Longhi C. (1999), Networks, collective learning and technology development in innovative hightechnology regions: the case of Sophia Antipolis, Regional Studies, Vol.33 nº 4, 333-324.

Longhi C. (2003), Local systems and networks in the globalisation process, Distretti, pilastri, reti. Italia ed Europa, Accademia Nazionale dei Lincei and Fondazione Edison, Roma 8-9 April. 
Longhi C., Quéré M. (1994), Sophia-Antipolis : Vers une redéfinition du projet, Rapport de recherche, CNRS-LATAPSES.

Lorenzen M., Foss N. (2003), Cognitive coordination, institutions and clusters: an exploratory discussion, in Brenner T. (Ed) The influence of co operations, networks and innovations on regional Innovation Systems, Cheltenham Edward Elgar.

Lundvall B. Å., Johnson B. (1994) “The Learning Economy”, Journal of Industries Studies, Vol. 1, $\mathrm{n}^{\circ} 2$, December, pp.23-42.

Markusen, A. (1996), Sticky places in slippery spaces: a typology of industrial districts, Economic Geography, 72(3), 293-313.

Maskell, P., Malmberg A. (1999), Localised Learning and industrial competitiveness, Cambridge Journal of Economics, 23, 167-185.

Morrison A. (2004) Do leading firms feed industrial districts? Evidence from an Italian furniture districts, Working paper presented DRUID conference, January 2004.

Nahapiet J., Ghoshal S. (1998), Social capital, intellectual capital, and the organizational advantage, The Academy of Management Review, vol. 23,. 242-266.

Nesta, L., Saviotti P. (2006), Firm knowledge and market value in biotechnology, Industrial and Corporate Change, 15(4):625-652.

Nooteboom B. (2003) Problems and Solutions in Knowledge transfer, in Brenner T. (ed) The influence of co operations, networks and innovations on regional Innovation Systems, Cheltenham Edward Elgar.

Orlikowski W. (2000), Using technology and constituting structures: a practice lens for studying technology in organizations. Organization Science, vol. 11, n4, pp. 404-428.

Porter M. (2000), Location, competition and Economic Development: local clusters in a global Economy, Economic Development Quarterly, 14, $\mathrm{n}^{\circ}$ 1, 15-34.

Richardson G.B. (1972) “The Organization of Industry”, Economic Journal, vol. 82, n³27, 883-896.

Roberts J., (2000), From know-how to show how, Questionning the role of information and communication technologies in knowledge transfer, Technology Analysis \& Strategic Management, December, vol.12, Iss.4, 429-443. 
Romme A.G.L., Endenburg G., 2006, Construction Principles and Design Rules in the case of Circular Design Organization. Organization Science, vol.17, n², pp. 287-297.

Rouby E., Thomas C. (2004), La codification des compétences organisationnelles : l'épreuve des faits, Revue Française de Gestion, March/april, nº 149, 51-68.

Rychen F., Zimmermann (2006), Clusters in the global knowledge based economy: knowledge gatekeepers and temporary proximity, Working paper, GRECAM Marseille.

Szulanski G., Cappetta R., JensenJ. R. (2004), When and How trustworthiness Matters: Knowledge Ttransfer and the Moderating Effect of Causal Ambiguity, Organization Science, Vol. 15, September-October, 600-613.

Torre A., Rallet A, 2005, Proximity and Localization, Regional Studies, Vol. 39.1, February, 47- 59.

Van de Ven A.H., Johson P. E., 2006, Knowledge for Theory and Practice. Academy of Management Review, Vol.31, n4, pp. 802-821.

Van Haken J. E., 2005, Management Research as a Design Science: Articulating the Research Products of Mode 2 Knowledge Production in Management. British Journal of Management, vol.16. pp. 19-36.

Veltz, P. (1993) D'une géographie des coûts à une géographie de l'organisation. Quelques thèses sur l'évolution des rapports entreprises/territoires, Revue Economique, ${ }^{\circ} 4$.

Zahra, S. A., and George, G. (2002), Absorptive Capacity: A Review, Reconceptualization, and Extension," Academy of Management Review (27:2), 185-203. 


\section{Appendix}

The co-development approach adopted for the KMP project requires a mechanism of high interaction locally. The interaction mechanism was organised around five main modalities:

i. Exploratory interviews of potential users (firms, organisations of regional development and research organisations). This first, familiarisation stage enables the actors to gain an understanding of the purposes of the tool, of the reasons why the client wishes to develop it, and to identify the key actors for the project.

ii. Semi-directive interviews of pilot users. Two types of interviews were conducted: The first type of interviews aimed to identify and map the different actors' competencies while the second type of interviews aimed to detect the practices and logics of action that recur during the construction of partnerships or projects of local development (user scenario)

iii. Ad hoc committees with the pilot users. These committees had a supporting function in specific codification processes and in determining the common space and establishing the ontologies of competencies.

iv. Pilot committees. The latter made it possible to evaluate and present (every three months) the intermediary results of the research team to the pilot users; This stage is essential to ensure the involvement of the users, to validate the legitimacy of the research team and to promote trust between the different stakeholders.

v. Interviews the purpose of which was to evaluate the solution, so as to be able to test, towards the end of the project, the elements proposed.

The table below is a synthesis of these different interactions between the researchers and local actors. 


\begin{tabular}{l|c|c|c|c} 
& $\mathbf{2 0 0 1 - 2 0 0 2}$ & $\mathbf{2 0 0 3}$ & $\mathbf{2 0 0 4}$ & $\mathbf{2 0 0 5 - 2 0 0 6}$ \\
\hline Exploratory interviews & 26 & & & \\
\hline Semi directive interviews : mapping & & 31 & 33 & \\
\hline Semi directive interviews : user scenario & & 24 & 28 & \\
\hline Ad hoc committees & 22 & 30 & 24 & 19 \\
\hline Pilot committees & 1 & 5 & 3 & 1 \\
\hline Evaluation of the device & & & 12 & 9
\end{tabular}


Figure 1: Potential absorptive capacity and realized absorptive capacity

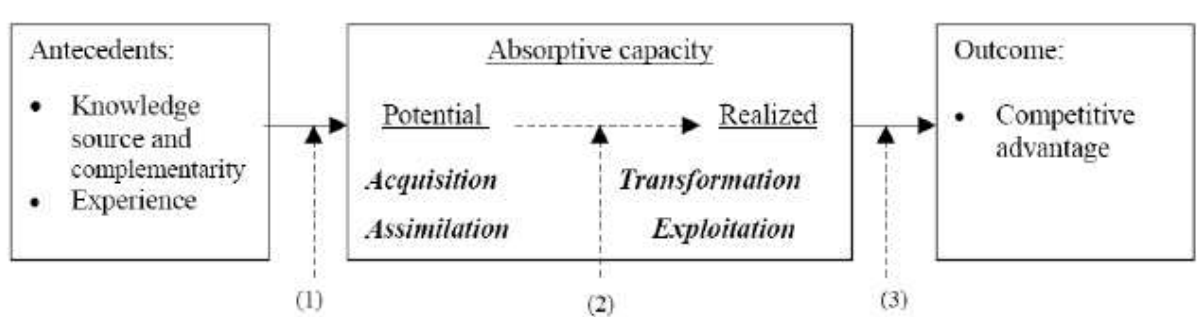

(1): activation triggers (internal/external)

(2): social integration mechanisms

(3): regimes of appropriability

Source: Zahra and George, 2002, p. 192.

Figure 2: The ICT cluster in Sophia Antipolis

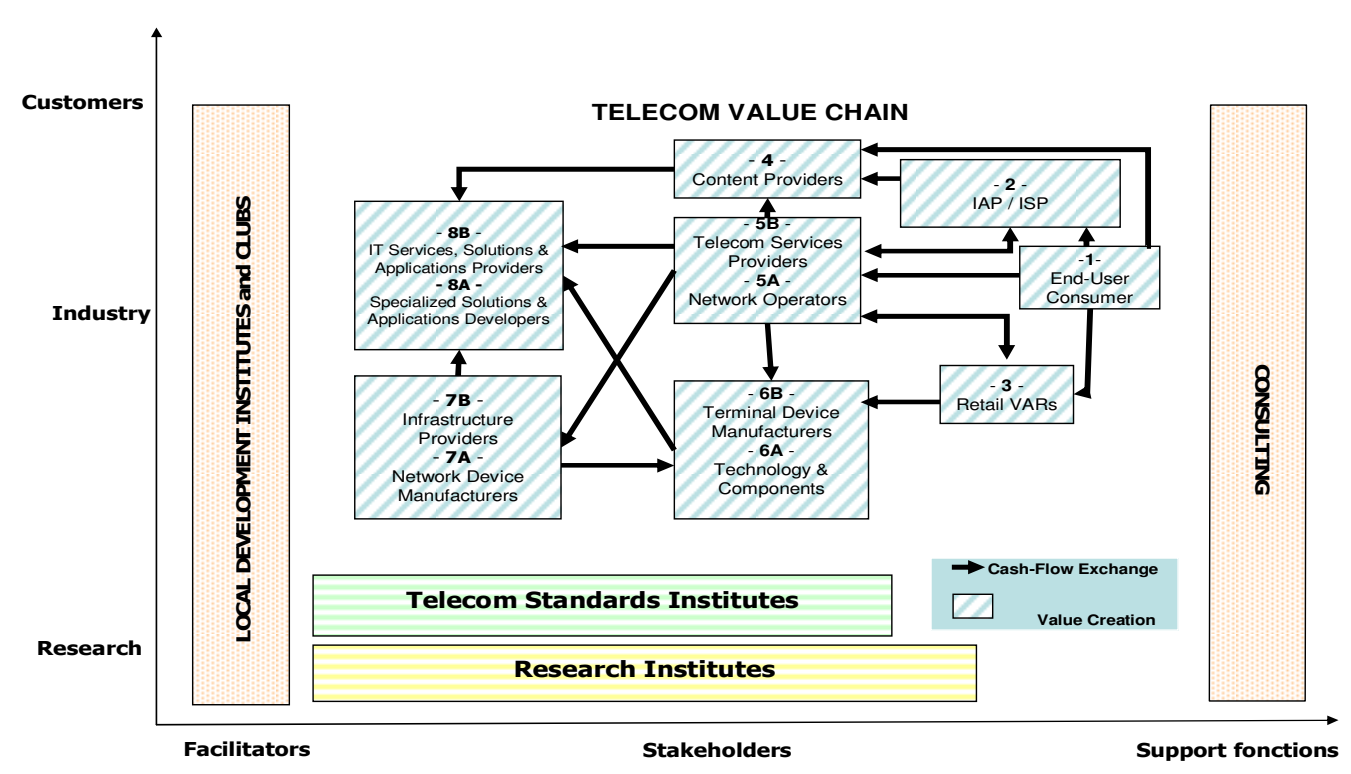

Source: Our research. 


\footnotetext{
${ }^{1}$ In French 'Pôles de Compétitivité'.

${ }^{2}$ In contemporaneous economies, this problem can be solved through the existence of 'local buzz' or 'global
} pipelines' (Bathelt, Malmberg, Maskell, 2002). The notion of 'local buzz' refers here to the 'Marshallian atmosphere', particularly the fact that a milieu could emit a lot of noise. More precisely "buzz" refers to the information and communication ecology created by face-to face- contacts, co-presence, co-location of people and firms within the same industry and place or region (Bathelt, Malmberg, Maskell, ibid, p. 11). The term of global pipelines refers to the channel used in distant interactions for opening the cluster and establishing systemic linkages with external sources of information.

${ }^{3}$ Notably if the distance is too wide, it may become an obstacle to the efficient combination of knowledge within a group of closely located firms.

${ }^{4}$ Indeed ' $(\ldots)$ a cluster which is more or less empty because its important actors are constantly travelling the world in order to build and maintain an extensive pipeline system will of course run an obvious risk of becoming less vibrant' (Bathelt, Malmberg and Maskell, 2002, p. 24). See also (Bresnahan, Gambardella and Saxenian 2001) in the same vein.

5 Pierre Lafitte was then Director of the renowned Ecole Nationale des Mines de Paris, one of French's 'Grandes Ecoles'.

${ }^{6}$ These activities now represent around $75 \%$ of technology jobs in the technopole, involving both large French and international companies ( $R \& D$ centres) and units of large research institutions.

${ }^{7}$ The acronym stands for CNRS (Centre National de Recherches Scientifiques i.e. National centre of scientific research) and INRIA (Institut National de Recherche en Informatique Appliquée i.e. National Research Institute on informatics an Automation).

${ }^{8}$ Many still have sub-contracting relationships with their parent firms and have maintained a high level of informal interactions to solve problems

${ }^{9}$ Indeed, this qualified labour force is related to the ICT sector - characterised by a high turnover rate - which has given rise, in Sophia Antipolis, to new behaviours in terms of labour market.

${ }^{10}$ More than half of the Sophiapolitan jobs are high-qualification jobs (executives and engineers) and in the information technology sector the proportion rises to over $70 \%$. 
${ }^{11}$ KMP Project has been subsidized by the Minister of Telecommunication RNRT network (Réseau National de recherches en télécommunications) http://www.telecom.gouv.fr/rnrt/projets/res_02-88.htm.

12 The acronym GREDEG stands for Groupe de Recherche en Droit Economie et Gestion, GET : Groupe des Ecoles de Télécommunications. ENST: Ecole Nationale de Sciences et de Télécommunications.

13 This 'step-by-step' approach enabled the actors to progressively get involved in the process of adoption/adaptation of the prototype (Latour, 1989) and fostered trust relations among all the partners of the project (Lazaric and Lorenz 1998). The validation rule was crucial in sustaining cooperation between the different networks of practice and members (the project team and the advisory team) without which it would have been impossible to give a sense to this dynamic (Lazaric, 2003).

${ }^{14}$ Design methodologies are specific modes of engaging in research. Especially, they are characterized by an active intervention process in the system in which the researchers act. In this perspective, a new figure of "engaged scholarship", in which researchers and practitioners co-produce knowledge has emerged in the 90's (David, 2000, Hatchuel 2005, Van Haken, 2005, Van de Ven and Johson, 2006). This new figure, called "mode 2 knowledge production" is multidisciplinary and aims at solving complex and relevant field problems.

${ }^{15}$ According to the structurational approach (Orlikowski, 2000), a separation between the designers' world from the users' world has been introduced.

${ }^{16}$ Uses scenarios were the following ones: 1) competencies description and storage by TV members, 2) the TV cluster exploration and 3) queries when actors look for a partner.

${ }^{17}$ This permanent involvement of the Telecom Valley association with the advisory team generated a dialogue concerning the limits and possibilities of codification, and in the process gave rise to a dynamic that went far beyond the initial objective a simple technical project. Progressively the members of the network adopted these ideas as their own and the Telecom Valley association imagined other scenarios for the development of the local ICT sector, which had not been part of the initial plans.

18 The construction of the Telecom Value Chain was based on the MIT "Telecom Value Chain Project" (URL: http://mitsloan.mit.edu/research/clockspeed/main.html) and was developed by a think-tank including both Telecom Valley members involved in the KMP project and researchers.

${ }^{19}$ For instance, the local subsidiary of Hewlett-Packard (formerly Compaq) designs and commercialises Telecom Network Infrastructure solutions while the parent company is generally known to design and manufacture computer devices and solutions. 


\footnotetext{
${ }^{20}$ Firms and LDIs have largely adopted this representation of potential combinations inside the cluster in order to create opportunities of promoting the cluster abroad.

${ }^{21}$ PACA stands for Provence Alpes Côte d'Azur.

${ }^{22}$ SCS stands for : Solutions Communicantes Sécurisées.

${ }^{23}$ Thus, the organisations located in the area had to clearly position themselves, which has led them to clearly define their logic of action and avoids "congestion effects" and problems of visibility between these various associations. The Vice-President of Telecom Valley claimed in 2005 that KMP has contributed to a clear identification of the clubs, allowing to achieve an efficient exploitation of competencies in Sophia Antipolis, the position and interests of all concerned being clear and known to all. The chairperson of the "club Energie" emphasizes that such clearly defined logics of action contribute to the emergence of a collective identity, a collective identity that "will enable Sophia Antipolis to develop in a sustainable manner".
} 